\section{STANFORD RESEARCH INSTITUTE, CALIFORNIA}

\section{REPORT FOR 1953}

$\mathrm{T}$

HE report for 1953 of the Stanford Research Institute, California*, states that contract research at the Institute increased by 18 per cent to 6.5 million dollars, the percentage of government research declined from 61 per cent in the first quarter to 49 per cent at the end of the year, while industrial research projects increased by 7.9 per cent on 1952 and 78.5 per cent on 1951. Of the 382 projects carried on during the year, 234 were for commercial clients and 109 for government agencies, while 39 studies were initiated or continued by the Institute as part of its plan for aiding the technological development of the region. Some 9 per cent of the Institute's revenue during the past three years has been expended on international activities, while a 30 per cent expansion in staff brought the total to 674 at the end of the year, the increase in professional staff in 1953 being 126 .

The present research programmes are in physical and biological sciences, engineering, economics, and certain applications of industrial psychology and sociology. Much effort in 1953 was directed towards the automatic assembly of equipment, control of processes and handling of large amounts of standardized data. Automatic processing and control were applied to a number of instruments, and a major programme was concerned with the development of improved machines and methods for the automatic fabrication of electronic equipment. A preliminary exploration of the possibility of constructing an input-output table for the flow of goods and services in the economy of the eleven western States of the United States was initiated, as well as a study of the impact of the aluminium industry on the economy of the Pacific North-West. A continuous process in which sawdust is held in fluidized suspension in a reactor is facilitating the preparation of chemicals from wood waste, while new lubricants for application at high temperatures have been developed experimentally and the physical properties of moulding resins were being correlated with structure to permit the preparation of new products with the desired combination of properties. A fundamental study of shock-wave behaviour in solid materials has led to a continuing programme on the application of the general laws of explosive shock waves to specific problems.

Another study is concerned with systematizing the use of selected common weeds as indicators of atmospheric pollution, while several field studies were concerned with the nature of the damage to commercial crops and vegetation by fluorides. A new instrument has been developed, utilizing a tape impregnated with a substance that loses its fluorescence on contact with gaseous fluorides, which gives an accurate record of atmospheric fluorides. Tracer techniques have made it possible to determine the contribution made by contaminants from a particular source to the total atmospheric contaminants in a given area. An extensive study of the requirements for airborne antennæ used in a long-range air-to-ground communications on military aircraft was completed during the year, while the

* Stanford Research Institute. Annual Report. Pp. 48. (Stanford, Calif.: Stanford Research Institute, 1954.)
Institute continued to participate in the application of operational research techniques both in defence problems and in industrial problems. Besides the development of new research techniques and instruments, the Institute has organized a techno-economic approach for assessing quickly the potential prospects of new products and markets.

\section{CHEMICAL RESEARCH LABORATORY, TEDDINGTON REPORT FOR 1953}

$T$ HE report of the Chemistry Research Board, signed by the chairman, Prof. E. L. Hirst, and the report of the director of the Chemical Research Laboratory, Teddington, Dr. D. D. Pratt, comprise the publication entitled "Chemistry Research 1953"*, which has recently appeared. 'To these are appended lists of committees of the Board, of staff of the Laboratory on December 31, 1953, of publications and patents in 1953, of metals held by the Pure Metals Committee, of standard substances available and of species in the National Collection of Industrial Bacteria. During the year the Chemistry Research Board endorsed a recommendation that chemical engineering should be added to the programme of the Laboratory, and, although such activities are at present planned on a modest scale, the Board points out that considerable additions to staff and accommodation will be required. The Board has also endorsed the recommendation of the Microbiology Committee that the Laboratory should pursue its investigations on the microbiological production of sulphur using sewage sludge as source of carbon as far as laboratory large-scale experiments to provide data for pilot-plant operation, and experiments have also been made on the simultaneous production of carbon and methane, which should offer considerable savings in capital and operating costs.

Commenting on the provision of standard materials by the Laboratory, the director points out that, since the National Collection of Industrial Bacteria was formed in $1950,2,505$ cultures have been distributed; and, of the 814 distributed in 1953, 535 were to research and educational and 279 to industrial establishments. Some effort is now being devoted to research on the maintenance of these cultures, particularly with reference to the viability of the organisms under freeze-drying conditions. The Laboratory has now forty-one reference specimens of organic compounds available, including five added during the year, and supplied 355 samples compared with 256 in 1952. The Board regards this work as a most valuable contribution to the nation's scientific work. A stock of twenty-six pure metals is also maintained, and the Pure Metals Committeo has noted, as a result of scientific developments in the field of semi-conductors, a growing demand for metals of a much higher degree of purity ( 99.999 per cent). Among the advisory work of the Laboratory, the director's report specially mentions that on immersed corrosion, underground corrosion and atmospheric corrosion in which services have been rendered to industrial firms and public bodies in

* Department of Scientific and Industrial Research. Report of the Chemistry Research Board with the Report of the Director of the Chemical Research Laboratory, for the year 1953. Pp. iv +73 . (London: H.M.S.O., 1954.) 2s. $6 d$. net. 